\title{
Evaluation and Literature Review on the Growth of listed Companies on Second Board in China
}

\author{
Zhang Bo ${ }^{1, \mathrm{a}}$, Song Siqi ${ }^{2, \mathrm{~b}}$ \\ 1 Shenyang Aerospace University, college of economic and management, Shenyang daoyi economic district, daoyi south street 37 \\ 13604075316, CN86 \\ ${ }^{2}$ Shenyang Aerospace University, college of economic and management, Shenyang daoyi economic district, daoyi south street 3715504147826 , \\ CN86
}

\begin{abstract}
Listed company on second board refers to the general name of the company which is supervised and managed by the gem market all over the world after being examined and approved by the relevant departments. It aims to help develop small and medium-sized companies, especially high-tech enterprises with fast development and sound economic operation, so that enterprises can avoid financial risks, provide a broader development platform for China's high-tech enterprises, and enrich the diversity of the capital market. To sum up, it is particularly important to study the growth of listed companies on second board. Based on the summary of relevant domestic and foreign studies, this paper made an in-depth discussion on the influencing factors and evaluation methods of the growth of listed companies on second board, comprehensively analyzed the growth of small and medium-sized companies, and summarized relevant theories and puts forward suggestions.
\end{abstract}

\section{RESEARCH STATUS OF GROWTH FACTORS AT HOME AND ABROAD}

\subsection{Abroad Research Status of Growth Factors}

For the growth of listed companies on second board, foreign research was earlier 20 years than domestic research. Penrose believed that the resources that enterprises can make full use of, especially those that are effective and can be flexibly mobilized within certain management scopes, provided a broad platform for the business expansion of enterprises and became the key to the further expansion and maturity of the enterprise market [1]. Mye and Turnbull used the results of multiple linear analysis to draw a conclusion that the higher the debt ratio, the worse the growth of the company, and the inverse correlation between the two based on the correlation between the market development of a company and the actual options of expected investment opportunities. At the same time, factors related to the growth of an enterprise included the following aspects: the industry market where the enterprise was located, development scale of the company, financial status, internal management, etc. [2]. Krugman introduced the regional growth theory. He argued that the growth of a company was largely influenced by its geographical location. Due to the different geographical conditions of the company's actual production, product production, delivery and product sales profit would show a different impact. The company's actual operating status and product sales volume could reflect the company's product profit margin [3]. Solvay and Sanglier argued that the growth of a company depends on cyclical changes in products led by consumer demand and the impact of continuous technological innovation. The cyclical change of products influenced by consumer demand enhanced the growth of the company. However, a company's potential production capacity can only be improved through long-term technological progress to increase the actual output of products and reduce the production cost. In addition, short-term fluctuations in economic demand can affect the company's production potential, which can be translated into the growth performance of the company to some extent [4]. Thorsten used the official data of 54 countries for quantitative analysis. The influence of capital sources, regulations and corruption on the future development of listed companies. Through data comparison, it was concluded that the influence of the above factors on the growth of the company was limited by the production volume of products. In addition, compared with European and American countries, in some economically underdeveloped regions, capital sources, regulations and corruption had a strong impact on the growth of listed companies [5]. Thorsten and Asli et al. studied more than 4000 companies from 54 countries, they did analysis on financial evaluation, legal system and corruption three aspects for $80 \%$ listed companies on second board and studied the effect of the above three factors on enterprise growth, it was concluded that firm size had an impact on profitability and potential profit conclusions [6]. 


\subsection{Domestic Research Status of Growth Factors}

Domestic scholars mainly focused on the small and medium-sized boards and the main board, while relatively few of them made empirical analysis on the listed companies on second board. Domestic analysis of growth factors of listed companies on second board tends to focus on segmentation factors, such as fixed asset investment, financial status, market competitiveness, management level, credit willingness, etc. The influencing factors of most companies' growth research were selected from the companies' own characteristics.

Hui Encai analyzed the development status of listed companies from internal and external factors. Internal influences included the core competitiveness of the enterprise, the ability of products to meet the needs of consumers, the internal financial status of the company and the ability of the company's senior management that responded to the development philosophy. External influences included national macro-control and policy tendency, industry market demand, preferential policies that enjoyed by enterprises, group holding advantages of listed companies. Yao Yi, Long Gejing and Liu Jinhua analyzed the relationship between corporate reputation, willingness and growth of listed companies and its influence degree from the perspective of willingness support. The empirical results showed that the credit and willingness of enterprises were important factors influencing the growth of enterprises and had a negative effect on the growth of enterprises[7]. Zhang Xianfeng studied the factors affecting the growth of listed companies from the perspective of technology innovation indicators, and analyzed them from three perspectives: brand effect, technology development capability and production patent. It could be concluded that listed companies on second board were less likely to contribute to scientific and technological innovation, their development was constrained, and their capital was integrated with high investment risks through analysis[8]. Zhang Jie and Wang Jin-ping studied the growth of listed companies with proprietary knowledge from the perspectives of industry environment and corporate governance. After examining the performance of listed companies from 2010 to 2012, it was concluded that the shareholding mode and the allocation of senior leaders have a great effect on the growth of companies. Zhu Yuesheng explored the impact of asset structure on growth of listed companies on second board from the perspective of enterprise economic resource allocation [9]. Ren Tongtong studied the impact of heterogeneous investors' shareholding on the growth of companies on the second board[10].

Table1. RESearch statistics of growth factors at home and abroad

\begin{tabular}{|c|c|c|}
\hline Time & Scholar & Research \\
\hline 1997 & $\begin{array}{l}\text { Mye and } \\
\text { Turnbull }\end{array}$ & $\begin{array}{l}\text { The debt ratio is negatively related to the } \\
\text { growth of the company. }\end{array}$ \\
\hline 1991 & Krugman & $\begin{array}{l}\text { The author introduced the regional growth } \\
\text { theory. }\end{array}$ \\
\hline
\end{tabular}

\begin{tabular}{|c|c|c|}
\hline 1998 & $\begin{array}{l}\text { Solvay and } \\
\text { Sanglier }\end{array}$ & $\begin{array}{l}\text { The growth of a company depends on } \\
\text { cyclical changes in products led by } \\
\text { consumer demand and the impact of } \\
\text { continuous technological innovation. }\end{array}$ \\
\hline & Hui Enca & $\begin{array}{l}\text { The author analyzed the development } \\
\text { status of listed companies from internal } \\
\text { and external factors. }\end{array}$ \\
\hline 2005 & Thorsten & $\begin{array}{l}\text { The factors on the growth of the company } \\
\text { was limited by the production volume of } \\
\text { products. }\end{array}$ \\
\hline 2007 & $\begin{array}{l}\text { Yao Yi, Long } \\
\text { Gejing and Liu } \\
\text { Jinhua }\end{array}$ & $\begin{array}{l}\text { The empirical results showed that the } \\
\text { credit and willingness of enterprises were } \\
\text { important factors influencing the growth } \\
\text { of enterprises and had a negative effect on } \\
\text { the growth of enterprises. }\end{array}$ \\
\hline 2012 & Zhang Xianfeng & $\begin{array}{l}\text { Listed companies on second board were } \\
\text { less likely to contribute to scientific and } \\
\text { technological innovation, their } \\
\text { development was constrained, and their } \\
\text { capital was integrated with high } \\
\text { investment risks through analysis. }\end{array}$ \\
\hline 2013 & $\begin{array}{l}\text { Zhang Jie and } \\
\text { Wang Jin-ping }\end{array}$ & $\begin{array}{l}\text { The author studied the growth of listed } \\
\text { companies with proprietary knowledge } \\
\text { from the perspectives of industry } \\
\text { environment and corporate governance. }\end{array}$ \\
\hline 2015 & Zhu Yuesheng & $\begin{array}{l}\text { The author explored the impact of asset } \\
\text { structure on growth of listed companies on } \\
\text { second board from the perspective of } \\
\text { enterprise economic resource allocation. }\end{array}$ \\
\hline 2017 & Ren Tongtong & $\begin{array}{l}\text { The author studied the impact of } \\
\text { heterogeneous investors' shareholding on } \\
\text { the growth of companies on the second } \\
\text { board. }\end{array}$ \\
\hline
\end{tabular}

\section{RESEARCH STATUS OF COMPREHENSIVE INDEX GROWTH AT HOME AND ABROAD}

Compared with the comprehensiveness of comprehensive indexes, single index evaluation focuses on one aspect of enterprises. For example, profit margin, fixed asset investment, price-to-book ratio, competitiveness of enterprises and their products, etc. The study on enterprise growth by single-index growth evaluation method is conducive to the analysis and understanding of enterprise managers, and facilitates managers and functional departments to quickly and accurately find out the reasons. But the single index growth evaluation method has its onesidedness, in order to make up for the lack of single index evaluation, through the comprehensive index to consider the growth of enterprises. This paper focuses on the analysis of the growth of comprehensive indicators at home and abroad.

\subsection{Abroad Research on the Comprehensive Growth Indicators}

Foreign literatures mainly monitored and evaluated the growth of companies from different directions. MacMillan et al. divided the growth indicators considering innovative enterprises on the second into 6 categories and 27 specific indicators. Including the cultural level of senior executives, basic level work experience, main business advantages, the industry, capital situation and corporate cultural connotation. Lang Larry et al. analyzed the financial situation, capital and enterprise development by selecting 
three growth indicators, namely, net investment in year $t+1$ / book value of fixed assets in year $t$, growth rate of capital expenditure and growth rate of employee number. Ardisshvili and Delmar et al concluded that the turnover and the number of employees would provide development space for small and medium-sized board r\&d companies. Chung-jen Chen and chin-chen Huang used AHP method to analyze the growth of the second board R\&D enterprises based on seven comprehensive evaluation criteria. The results showed that consumer demand, regional preferential policies, land allocation research and development capacity, product correlation degree, supporting equipment these six factors influence the company's development force from large to small. In 2005, Erkki used the non-static evaluation method and took 85 high-tech enterprises in the Netherlands as the research objects. The system was composed of five internal factors and two external factors as well as the causal chain connecting them. Internal impact: processing methods, materials and equipment, finished products, sales profits, production costs, etc. External influences include: capital control and market share. Moreover, the research shows that the finished products, sales revenue and supporting facilities play a significant role in the development of the company [11]. Tarnoczi Tibor, Kulcsar Edina, Droj Laurentiu believed that growth is the effective growth of some economic indicators, so they select internal growth rate and sustainable growth rate to evaluate enterprise growth.

\subsection{Research on the Comprehensive Growth Indicators in China}

Wang Yefei used financial indicators as the growth evaluation index, and connected with the China securities regulatory commission on the second board to measures the growth of listed companies through extracting the business revenue growth and operating profit growth rate, growth rate of gross profit, net profit growth rate, growth rate of total assets and net asset growth rate that reflects the enterprises' expanding capacity, profitability indicators. Liu Liang selected indicators reflecting the enterprise's technological innovation ability, profitability, solvency, operational ability, development ability, shareholder profitability and employee quality to examine the enterprise's growth. Chen Yao divided the comprehensive evaluation on the growth of the companies on the second board into two aspects through integrating the factors at the present stage: micro growth and macro growth. In terms of micro growth, the four indicators of profitability, solvency, operating capacity and cash flow were selected to reflect the growth of listed companies on second board. In terms of macro growth, indicators reflecting capital structure, income quality and growth ability are selected as comprehensive indicators to study the growth of listed companies on second board. Yao Xue selected 343 listed companies on second board as samples, the unique characteristic of the second board in our country, the listed companies' growth ability, profit ability, risk control ability, operating ability, ability to obtain cash, risk level, management ability, innovation ability and so on eight aspects, 14 specific indicators to build the evaluation index system that included six common factors. Wang Jia used simplify, application and key points for the principle, the combination of qualitative and quantitative analysis method, the absolute value and the relative supplementary analysis process. Under the condition of the unity of financial indicators and non-financial indicators, she built the evaluation index system of the listed companies on the second board through correlation analysis and discrimination analysis and confirmatory factor test. The system included financial effectiveness and profitability, the power of human capital, technology and innovation ability three aspects that total of 14 growth evaluation indicators. Then mutation progression method was adopted to establish the evaluation model of growth of listed companies. She selected the 37 internet listed companies to do the empirical research, evaluate sample enterprise's growth, results showed that the financial effectiveness, profitability and strength of human capital were the main reasons for causing the differences of listed companies on second board. Liu liang selected 12 indicators that could reflect the growth of companies, and comprehensively measured the growth of companies through factor analysis based on the financial data of 170 listed companies on second board in the past three years. Four financial indicators that can represent the company's capital structure were selected, namely asset-liability ratio, long-term debt ratio, commercial credit ratio and equity financing ratio. On this basis, the model was empirically analyzed by means of multiple regression analysis, and the relevant hypotheses were verified. Ma Yuzhe selected the related data of 708 listed companies on the second board as research samples between 2014 to 2016 . He divided two types: the big enterprise size (size is greater than the sample mean) and small enterprise size (size is smaller than the sample mean) based on the mean of natural logarithm of final total assets, chosen asset-liability ratio and long-term capital debt ratio as the explained variable, sales net interest rate, period expense rate, $Z$ value as control variables, constructed comprehensive growth indicators from four dimensions of profitability, operation ability, investment income level and development ability and did regression analysis of the above variables. He selected twelve financial indicators as the basis of enterprise growth analysis, got he growth score sequence of listed companies on the second board, and built a multiple linear regression model.

\subsection{Summary}

Domestic and foreign scholars tended to use multi-factor index analysis method to investigate the growth of enterprises. Some scholars also considered the limitations of single factor index analysis method and the shortcomings of incomplete measurement of enterprise growth. To compensate for this, they used two or three factors. Therefore, the growth of enterprises should be considered from the business scope, market share, number of employees, management mode, capital flow, debt situation, financing income and other perspectives, and the growth of enterprises can be fully grasped through 
qualitative and quantitative analysis.

\section{RESEARCH STATUS OF GROWTH EVALUATION METHODS AT HOME AND ABROAD}

\subsection{Abroad Research Status of Growth Evaluation Methods}

Hassapis and Kalyvitis established a growth model reflecting the output relationship and stock prices, adopted the autoregressive method, selected relevant data of stock price changes and economic growth in seven countries and analyzed the relationship between the two [12]. Cefisa Ciccarelli and Orsenigo took industrial enterprises as sample objects and adopted the bayesian panel data method for research. The research showed that the growth rate and company size of each company in the same industry did not converge to the same limit distribution at the same time, and the growth rate was related to the size [13]. Coad and Rao used the regression analysis method to introduce the index of the compan"s innovation ability into the model to discuss whether the compan"s innovation ability has an impact on the company's growth, and the research showed that the company's innovation ability has a huge impact on the company's growth [14]. Park and Jang studied the internationalization development of catering enterprises by using factor analysis from the perspective of enterprise scale. The research showed that with the continuous expansion of enterprise scale, the growth and development speed of enterprises also increased [15]. Alex Coad adopted the quantile regression method to identify the differences in the impact of R\&D investment in different growth stages on the growth of companies, and found that companies in high growth stages had the strongest correlation between R\&D investment and growth, and innovation was the main reason for the rapid growth of star companies.

\subsection{Domestic Research Status of Growth Evaluation Methods}

The methods commonly used in China are the followings:

\subsubsection{Efficiency coefficient method}

The method is to determine the satisfaction value and disallow value respectively for each evaluation index. Taking the unallowable value as the lower limit, the degree of satisfaction of each index is calculated, which is converted into the corresponding evaluation value of each index, and finally the target comprehensive index is weighted. Since the allowable value and satisfaction value of each indicator are both the worst value and the best value of the industry, the efficiency coefficient method can better reflect the company's ranking in the industry. However, the disadvantage of this method is that different indicators cannot be assigned with different weights, so the growth of enterprises cannot be accurately measured. This efficiency coefficient method can not predict the future development trend of the company, nor can it conduct dynamic analysis of the company's financial situation, so the evaluation results obtained are not of practical significance.

\subsubsection{Two-dimensional judgment method}

It is suitable for evaluating the growth of China's listed companies on the second board. The two-dimensional judgment method measures the market share and competitiveness of an enterprise based on its geographical and economic period. When the two-dimensional judgment method is used to measure the growth rate and product quality of an enterprise, it is greatly affected by subjective factors. The standard value is set by the researcher in advance, and the expert opinion is involved more. At the same time, data redundancy, large amount of computation, need to rely on high quality programming computing software, it is the disadvantage of this method.

\subsubsection{Factor analysis}

It selects key indicators from a number of indicators, so that senior decision makers can use limited company resources to optimize and improve key indicators, thus achieving the effect of fundamentally solving the problem, shortening the period of enterprise tension, and accelerating the development speed of enterprises. The disadvantage of factor analysis method is that it is a comprehensive evaluation method, which has high requirements for data quantity and fitness. Therefore, the data demand of factor analysis method is large and the universality is poor. Compared with the single factor analysis method, it is impossible to make specific analysis and focus on a certain influence factor.

\subsubsection{Entropy method}

Entropy method is to determine the difference degree of the index according to the information entropy of the given index sample, and then judge the weight of the index. The greater the difference, the more information it contains, the more weight it should be given, and the greater the impact of this index on the growth of enterprises. The entropy method avoids the shortcomings of subjective factors in the selection of important indicators, thus making the evaluation results more objective and fair. At the same time, there are also disadvantages. Because the entropy method completely avoids the influence of subjective factors, it cannot be added to some obvious but unmeasurable influences, which is also the deviation of its evaluation results from the empirical value. Moreover, entropy method is a kind of comprehensive evaluation method with strong objectivity, which can not produce effect on the reduction of measurement dimension.

\subsubsection{Mutation series method}

According to the catastrophe theory, the catastrophe series method firstly decomposes the object in different levels of 
contradiction, then calculates the object in different levels by using the membership function generated by the fuzzy mathematics and the catastrophe theory, and finally classifies it as an evaluation method of the calculated value of a parameter. The fuzzy mathematics method is because there are some factors that cannot be simply evaluated when analyzing the growth of the second board, so the fuzzy mathematics method is used to directly evaluate the growth of enterprises quantitatively. The analytic hierarchy process is to decompose the complex problem into many sub-problems step by step and establish the hierarchical structure by classifying the elements according to the dominant relationship. The advantage of the abrupt progression method is that it takes into account the relative importance of each evaluation index and does not weight the selected index, so it has scientific rationality while reducing subjectivity, and the calculation process is simple but accurate. In addition, the methods to measure growth include neural network method, computer simulation of hybrid model and grey relational analysis.

\section{CONCLUSION AND EVALATION}

When Chinese and foreign scholars studied the growth factors of listed companies on second board, they mostly started from two perspectives. The first is the rational allocation of limited resources. At present, the management mode of listed companies on the second board provides space for the growth and development of enterprises to a large extent. The amount of assets, the number of employees, the level of high-tech support, the participation of shareholders and the degree of education, youth, professional level and position distribution of senior management will all play a role in the enterprise's management mode. The second is the influence of the policy on the growth of enterprises. For the growth of listed companies on second board, there is a u-shaped relationship between the proportion of senior executives' shareholding and enterprise growth. For private enterprises, the shareholding ratio of major shareholders is negatively correlated with the growth of the company. The largest shareholder absolute control, for the growth of enterprises will have a negative effect. When the shareholder holding capacity is low, the development of the enterprise can not play an incentive role. For familyowned enterprises, in the initial stage of the company, the merger and integration of resources, concerted efforts of internal personnel, a high degree of centralization and strong decision-making power will play a positive role in the expansion and development of the enterprise. However, with the expansion of the scale of the enterprise, the negative effects brought by this centralized system are gradually increasing. Due to insufficient control, the contradictions in the profit distribution of the internal management will further expand, thus restricting the growth of the enterprise. The change of the enterprise and the management mode of promoting modernization become the important way to break the bottleneck. At the same time, in order to share the risks in the process of investment expansion of enterprises, prevent the rupture of capital chain, increase private equity, use a variety of capital methods to effectively and rationally operate the existing resources of enterprises, also become an effective way to avoid enterprise risks. It also plays an important role in promoting the growth of enterprises to analyze the industry environment, optimize the allocation of senior management personnel, make full use of existing national and regional policies, and expand the mode of receiving resources.

The second board in China's listing threshold is lower than the main board, the regulatory system, information disclosure, trader conditions, investment risks and other aspects of the main board market is also significantly different. The reason lies in the different stages and levels of economic and stock market development in China and America. The second board market is the product of the integration of technological innovation and financial innovation. Due to the differences in the level of technology and economic development, the second board market does not have a unified model. It has different characteristics in different countries and regions. And with the social and economic development, the second board itself is also in constant development and change. In developed countries such as the United States, the growth enterprise market has matured after years of development, and the macro differences between the growth enterprise market and the main board market should be given more weight. The focus of the discussion has shifted to market operation cost, efficiency and other aspects of the micro structure. The second board market with the robust growth period has an important role China's capital market development. The second board market enterprises generally have higher growth, but the growth of different enterprises was significantly different. A variety of factors affect the growth of enterprises in the second board market, including environmental factors, industry factors, financial ability and technological innovation ability. At present, there are still some deficiencies in the development of listed companies on the second board in China, and the research on the second board enterprises should also focus on putting forward practical solutions to the problems. In terms of data acquisition, most domestic studies are limited to the previous annual data disclosed by the government, with poor timeliness and great influence from policy fluctuations. Moreover, most researchers only deal with the data and do not take into account the annual national policies of the year in which the data occurred, so they are not forward-looking. And different researchers, using different data processing methods, come to different conclusions, or even contrary. Therefore, it can not fully reflect the actual growth and development of the enterprise. The research on enterprises should be combined with the actual situation of enterprises, in-depth field investigation of enterprises at the current stage of development problems, obtain first-hand data, and draw accurate conclusions.

\section{ACKNOWLEDGMENT}

This paper is sponsored by Liaoning social science fund "Research on evaluation of liaoning pilot free trade zone's 
and development strategy research", subject No.L18BJY032. Liaoning provincial department of education project "Research on evaluation of international competitiveness of liaoning aviation manufacturing industry and countermeasures based on innovation perspective", project No.JYT19016. Shenyang science and technology bureau project "Shenyang science and technology conditions platform 2018 offline science and technology counseling service", project No. 2018SKJ.

\section{REFERENCES}

1. Penrose E. Theory of the growth of the firm. Oxford University Press, 1959, 253-264.

2. Churchill C, Lewis V L.The five stages of small business growth. Harv. Business Review, 1983 (3):30-50.

3. Krugman P.Increasing Returns and Economic Geography. Journal of Political Economy, 1991(99):483-499.

4. Zutshi. Growth of firns in developing countries. Journal of Development Economics, 2002(4):463481.

5. Frederic Delmar, Per Davidsson, William B Gartner. Arriving atthe High-growth Firm. Journal of Business

6. Michal.E.Porter. How competitive forces shape strategy[J]. Harvard business review . 1979.

7. Yao Yilong, Ge jing, Liu Jinhua. Research on the relationship between growth and credit willingness of listed companies. Southern finance, 2007 (10): 45-47.

8. Zhang Xianfeng. Research on value assessment of Chinese listed companies on the second board based on growth and innovation ability [D]. Jilin: Jilin university, 2012.

9. Zhu Yuesheng. Research on the influence of asset structure on growth of listed companies on the second board[D]. Tianjin: Tianjin university of science and technology, 2015.

10. Ren tongtong. Research on the influence of heterogeneous institutional investors' shareholding on the growth of gem companies [D]. Shandong: Shandong university of finance and economics, 2017.

11. Erika, K. Laitance. Dynamic performance measurement system: evidence from small Finnish technology companies [M], Scand.J.Mgmt, 2002, (18): 65-99.

12. Hassapis, Christis and Kalyvitis, Sarantis. Investigating the links between growth and real stock price changes with empirical evidence from the G-7 economies. The Quarterly Review of Economics and Finance, 2002, 42: 543-575.

13. Elena Cefisa, Matteo Ciccarelli, Luigi Orsenigo. Testing Gibrat's legacy: A Bayesian Approach to Study the Growth of Firms [J]. Structural Change and Economic Dynamics, 2007(18): 348-369.

14. Alex Coad, Rekha Rao. Innovation and Firm Growth in High-tech Sectors: A Quantile Regression
Approach[J]. Research Policy, 2008, 37(4):633-648.

15. Kangmin Park, Soo Cheong (Shawn)Jang. Firm Growth Patterns: Examining the Associations Management With Firm Size and Internationalization [J]. International Journal of Hospitality.2009, 9(19):110. 